\title{
O COORDENADOR PEDAGÓGICO: SUAS REAIS FUNÇÕES NO CONTEXTO ESCOLAR
}

\author{
Jéssica Barreto de Azevedo \\ Graduada em Pedagogia/ISECENSA/RJ \\ jessicabazevedo@hotmail.com
}

Liliana Azevedo Nogueira

Especialização em Piscopedagogia Institucional/UNESA/RJ

lilyan_24@hotmail.com

Teresa Cristina Rodrigues

Especialista em EaD / ISECENSA/RJ

tcris@censanet.com.br

\section{RESUMO}

Neste artigo, pretende-se investigar as práticas do coordenador pedagógico das escolas públicas e particulares de Campos dos Goytacazes, detectando o foco de sua atuação e uma delas é ser o elo integrador da ação que se concretiza no contexto educacional, bem como, refletir sobre os desafios e conflitos enfrentados na sua prática que permeiam o cotidiano deste profissional na comunidade escolar. O seu campo de atuação é muito amplo, envolvendo atividades relacionadas aos componentes curriculares, aprendizagem e construção de conhecimento, disciplina, ética, avaliação, materiais didáticos e a interação com a comunidade. Destaca-se também, a reflexão sobre o papel do Coordenador Pedagógico, pois é um profissional responsável por formar e manter a equipe escolar coesa, empenhada e firme no propósito assumido na proposta de trabalho da unidade escolar. Relata-se, ainda, questões sobre a função deste especialista junto ao corpo docente, acompanhando o professor em suas atividades de planejamento, docência e avaliação, no sentido de melhorar o processo de ensino aprendizagem. $\mathrm{O}$ relato das ações desencadeadas na escola está acompanhado dos principais requisitos pedagógicos que a equipe docente precisa para conquistar e obter um trabalho coerente e significativo. A significância deste projeto não pode ser alcançada de imediato, já que demanda sua aplicação, avaliação e permanente redirecionamento por parte da equipe escolar, da qual faz parte. As reflexões, ideias e propostas citadas, bem como a metodologia utilizada na construção deste artigo, baseiam-se em observações do cotidiano escolar desse profissional. É cabível, também, uma revisão de literatura que se alicerçam em pressupostos teóricos, que se dedicaram ao estudo da ação desse especialista, configurando-se esses referenciais em ampla contribuição para o entendimento da atuação própria do coordenador pedagógico.

Palavras - chave: Coordenador pedagógico; Escola; Funções escolares. 


\section{RESUMEN}

En este artículo, tenemos la intención de investigar las prácticas de la coordinadora pedagógica de las escuelas públicas y privadas en Campos dos Goytacazes, detectar el foco de sus operaciones y uno de ellos a la integridad del enlace de la acción que se lleva a cabo en el contexto educativo, así como reflexionar sobre los retos y conflictos que enfrentan en su práctica que impregna el trabajo diario de la comunidad escolar. Su campo de juego es muy amplia, en actividades relacionadas con los componentes curriculares, el aprendizaje y la construcción del conocimiento, la disciplina, la ética, la evaluación, los materiales de aprendizaje e interacción con la comunidad. También es digno de reflexión sobre el papel de la Coordinadora para la Enseñanza es un profesional responsable de crear y mantener un equipo de la escuela cohesionada, comprometida y firme en el propósito de hecho en el trabajo propuesto de la unidad escolar. Los informes también se pregunta sobre el papel del especialista de la facultad, junto con el profesor en su planificación, enseñanza y evaluación, para mejorar el proceso de enseñanza-aprendizaje. El informe de las acciones disparadas en la escuela principal está acompañada de los requisitos educativos que el personal docente necesario para conquistar y obtener un trabajo coherente y significativa. La importancia de este proyecto no se realice inmediatamente, ya que la demanda de su redirección ejecución, evaluación y permanente por el personal de la escuela, que es una parte. Los pensamientos, ideas y propuestas de la lista y la metodología utilizada en la elaboración de este artículo, basado en observaciones de la vida escolar diaria de un comerciante. Es conveniente, también, una revisión de la literatura que se basan en suposiciones de los teóricos que han estudiado la acción de este experto, la creación de estos puntos de referencia en una gran contribución a la comprensión del comportamiento de coordinador pedagógico propio.

Palabras clave: Coordinador pedagógico; Escuela; Funciones escolares.

\section{INTRODUÇÃO}

Vivemos em uma sociedade em que ocorrem inúmeras mudanças, de ordem política, social, econômica, ideológica. A escola, como instituição de ensino e de práticas pedagógicas, enfrenta muitos desafios que comprometem a sua ação frente às exigências que surgem. Os profissionais precisam estar conscientes de que os alunos devem ter uma formação cada vez mais ampla, promovendo o desenvolvimento das capacidades desses sujeitos. Para que isso aconteça, é necessária a presença do coordenador pedagógico consciente de seu papel, da importância de sua formação continuada e da equipe docente, além de manter a parceria entre pais, alunos, professores, direção e técnico-administrativo.

A função da coordenação pedagógica é gerenciar, coordenar e supervisionar todas as atividades relacionadas com o processo de ensino e aprendizagem, visando sempre à permanência do aluno com sucesso. Partindo desse pressuposto, podem-se identificar as funções formadora, articuladora e transformadora do papel desse profissional no ambiente escolar. 
A função formadora, do coordenador precisa programar as ações que viabilizam a formação do grupo para qualificação continuada desses sujeitos, conseqüentemente, conduzindo mudanças dentro da sala de aula e na dinâmica da escola, produzindo impacto bastante produtivo e atingindo as necessidades presentes. (CLEMENTI, 2003, p.126)

Assim, muitos formadores encontram na reflexão da ação momentos riquíssimos para a formação. Isso acontece à medida que professores e coordenadores atuam em parceria, observando, discutindo e planejando, vencendo as dificuldades, expectativas e necessidades, requerendo momentos individuais e coletivos entre os membros do grupo, atingindo aos objetivos desejados.

As relações interpessoais permeiam a prática do coordenador que precisa articular as instâncias escola e família, sabendo ouvir, olhar e falar a todos que buscam a sua atenção.

O coordenador pedagógico deve identificar as necessidades dos professores e com eles encontrar soluções que priorizem um trabalho educacional de qualidade.

Esse profissional tem que ir além do conhecimento teórico, pois para acompanhar o trabalho pedagógico e estimular os professores é preciso percepção e sensibilidade para identificar as necessidades dos alunos e professores, tendo que se manter sempre atualizado, buscando fontes de informação e refletindo sobre sua prática. Faz-se necessário destacar que o trabalho deve acontecer com a colaboração de todos. O coordenador deve estar preparado para mudanças e sempre pronto a motivar sua equipe.

Dentro das diversas atribuições do coordenador está o ato de acompanhar o trabalho docente, sendo responsável pelo elo entre os envolvidos na comunidade educacional. $\mathrm{O}$ relacionamento entre o coordenador e o professor é um fator de suma importância para uma gestão democrática, mas para que isso aconteça são necessárias estratégias bem formuladas, para que não perca seu foco no decorrer do caminho.

O coordenador precisa estar sempre atento ao cenário que se apresenta a sua volta, valorizando os profissionais da sua equipe e acompanhando os resultados. Cabe ao coordenador refletir sobre sua própria prática para superar os obstáculos e aperfeiçoar o processo de ensinoaprendizagem. O trabalho em equipe é fonte inesgotável de superação e valorização do profissional.

Torres (1994) defende a ideia de que o coordenador pedagógico é um agente responsável pela formação continuada dos professores, subsidiando e organizando a reflexão, estimulando o processo de decisão visando à proposição de alternativas para superar os problemas da prática. Acredita que ele é uma figura essencial nesse processo integrador e articulador de ações. 
Ao coordenador pedagógico vem sendo solicitada essa função na expectativa de que ele opere como mediador das reflexões sobre a prática, em um contexto de trocas simétricas e acolhida, para ouvir e falar com os professores. Além da formação de professores, Guimarães e Villela (2000) destacam que o coordenador tem três níveis de atuação, que não se excluem: resolver os problemas instaurados; prevenir situações problemáticas previsíveis e promover situações saudáveis do ponto de vista educativo e sócio afetivo.

Adotando a definição de Leite (2000, p. 63-64), a coordenação pedagógica está sendo entendida neste texto como "um conjunto de atividades executadas no sentido de garantir que ocorra a organização docente em todos os níveis previstos". Tais atividades implicam desde garantir as condições logísticas até o acompanhamento de cada etapa do processo de organização.

Cabe também à coordenação pedagógica perceber as dificuldades e necessidades da equipe de docentes, na medida em que organiza e orienta a discussão coletiva a respeito do planejamento das práticas pedagógicas, permitindo que todos explicitem as suas opiniões e sugestões.

Ainda segundo Leite (2000), a formação continuada de professores é aquela que assume o desafio de idealizar e construir a escola como um ambiente educacional em que a formação e a prática pedagógica não ocorram de maneiras distintas, sendo articuladas com a gestão escolar, as práticas curriculares e as necessidades profissionais. Nesse processo, o professor tem oportunidade de assumir o seu papel de sujeito ativo, participando de forma decisiva em todas as etapas do trabalho escolar.

A busca do sentido da ação do coordenador pedagógico e sua constituição como formadora precisam ser refletidas e explicitadas coletivamente, para que cada um tenha a oportunidade de vir a se tornar mais consciente de sua forma de atuação e mais crítico com relação às (pré) concepções e perspectivas que nutre a respeito de seu trabalho.

A construção da identidade profissional e o fortalecimento de seu compromisso com o grupo de professores e alunos dependem da consciência crítica que professores e coordenadores têm frente à sincronicidade das dimensões políticas, humano-relacionais e técnicas de sua ação. Somente a consciência do dinamismo dessas dimensões permite o redirecionamento da percepção sobre a realidade, sobre nós mesmos e o outro, sobre nossa prática, a fim de que reavaliemos os critérios por meio dos quais nos posicionamos e nos direcionamos para essas realidades. (PLACO, 1994, p. 68).

Assumida a hipótese que o coordenador é um agente de formação de professores no interior das escolas, vários autores dedicam-se a pensar especificidade de sua tarefa e as competências e habilidades necessárias a essa função. 
A função do coordenador pedagógico dentro da escola nem sempre é bem delimitada. Muitos acham que o cargo do coordenador é auxiliar do diretor nas questões burocráticas. Outros acreditam que cabe a ele resolver os problemas disciplinares dos alunos. E seu papel muitas vezes é ocupado por outras funções. Porém, a tarefa do coordenador é fazer com que os professores se aprimorem na prática de sala de aula para que os alunos aprendam sempre. Para isso, ele só tem um caminho: realizar a formação continuada dos docentes da escola.

Há quem acredite que ensinar é uma vocação e, por isso, o "dom" nasceria com a pessoa. Outros afirmam que ele aprende por tentativa e erro, acumulando experiências de sala de aula. E ainda existem os que defendem que o domínio do "como ensinar" vem da mera reprodução de roteiros prontos de aulas e de atividades. A necessidade de haver formação continuada só surge quando o professor é visto como um profissional que deve sempre aperfeiçoar sua prática ao fazer um trabalho de reflexão sobre ela e tem contato com o conhecimento didático. É aí que surge o papel de formador do coordenador pedagógico, que se torna imprescindível para orientar esse processo. (NÓVOA, 2001)

Para bem cumprir a função, ele deve estar sempre atualizado (o que significa estudar muito) com as didáticas específicas - compostas dos saberes sobre os conteúdos, da forma de ensinar cada um deles e da maneira como as crianças aprendem.

Esse trabalho visa refletir sobre o trabalho desempenhado por este profissional em escolas do município de Campos dos Goytacazes/RJ, apontando suas reais funções dentro das instituições de ensino, observando se o conteúdo compreendido na teoria é realizado na prática.

\subsection{Problema}

- Qual o foco do trabalho dos coordenadores pedagógicos em escolas particulares e públicas de Campos dos Goytacazes?

\subsection{Questionamentos}

- Quais as funções do coordenador pedagógico na escola e sua contribuição na co-formação e supervisão dos processos de ensino-aprendizagem de professores e alunos?

- Que desafios o coordenador pedagógico encontra na realização do trabalho coletivo na integração curricular?

- Quais são as prioridades reais que o coordenador pedagógico precisa atender na prática cotidiana das escolas? 


\subsection{Objetivos}

\subsection{1 - Objetivo Geral}

- Investigar as práticas do coordenador pedagógico em escolas públicas e particulares de Campos, detectando o foco de sua atuação.

\subsubsection{Objetivos Específicos}

- Apontar as funções do coordenador pedagógico na escola e sua contribuição na coformação e supervisão dos processos de ensino aprendizagem de professores e alunos.

- Identificar os desafios que o coordenador pedagógico encontra na realização do trabalho coletivo na integração curricular.

\section{METODOLOGIA}

A realização desta pesquisa tem como objetivo apontar as reais funções do coordenador pedagógico dentro das escolas públicas e particulares de Campos dos Goytacazes. Realizamos uma pesquisa bibliográfica acerca do tema, assim como uma pesquisa de campo, buscando investigar a atuação do coordenador pedagógico.

No decorrer do trabalho é possível compreender, a partir de observações teóricas, as funções do coordenador pedagógico na escola e sua contribuição na co-formação e supervisão dos processos de ensino-aprendizagem de professores e alunos.

A aplicação de questionários em duas escolas públicas e três escolas particulares de Campos dos Goytacazes, permitiu coletar dados, identificando as reais prioridades do coordenador pedagógico e sua prática cotidiana nas referidas escolas.

Com essa pesquisa, espera-se que o coordenador pedagógico possa refletir sobre sua postura democrática e ética em função da extrema necessidade de administrar os conflitos existentes nas relações interpessoais e buscando sempre inovar o processo ensinoaprendizagem, por meio de uma prática participativa que envolva os agentes da educação. 


\section{ANÁLISE E DISCUSSÃO DOS DADOS}

A seguir, apresentamos os dados coletados a partir do questionário (em anexo) aplicado aos coordenadores de escolas públicas e particulares de Campos dos Goytacazes.

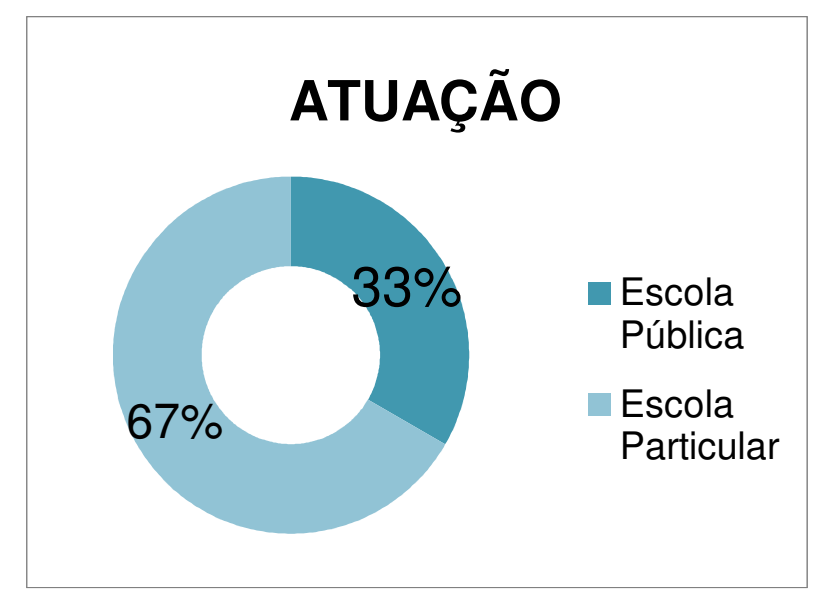

Gráfico 1 - Atuação dos coordenadores.

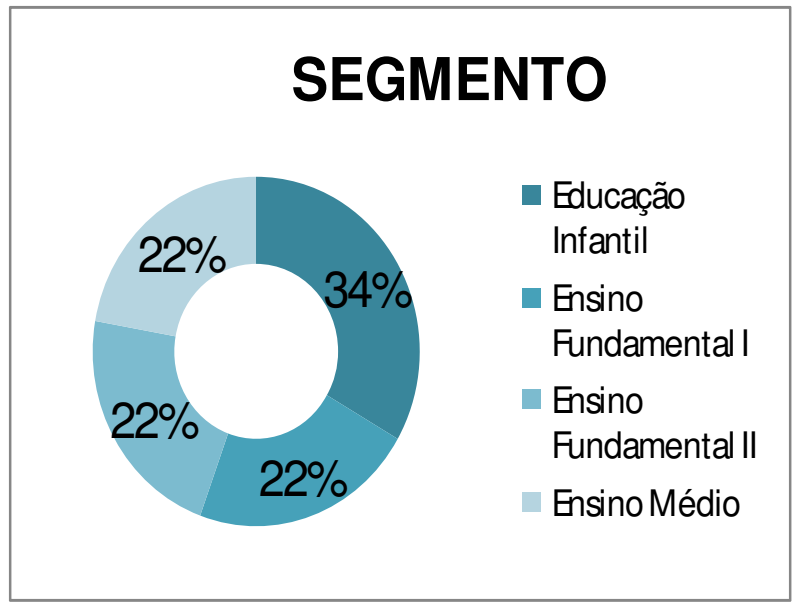

Gráfico 2 - Segmentos de atuação dos coordenadores.

A maioria dos coordenadores sujeitos dessa pesquisa atua em escolas particulares (67\%), como constatamos no gráfico 1 .

O gráfico 2 apresenta a atuação dos coordenadores entrevistados nos diversos segmentos da Educação Básica (Educação Infantil, Ensino Fundamental e Ensino Médio).

Diante das inúmeras mudanças que ocorrem na sociedade atual, de ordem econômica, política, social, ideológica, a escola, como instituição de ensino e de práticas pedagógicas, enfrenta muitos desafios que comprometem a sua ação frente às exigências que surgem. Assim, 
os profissionais que nela trabalham precisam estar conscientes de que os alunos devem ter uma formação cada vez mais ampla, promovendo o desenvolvimento das capacidades desses sujeitos.

Para tanto, torna-se necessária a presença de um coordenador pedagógico consciente de seu papel, da importância de sua formação continuada e da equipe docente, além de manter a parceria entre pais, alunos, professores, técnicos e direção.

A partir de dados coletados por meio de questionários direcionados a Coordenadores Pedagógicos da Educação Infantil, Ensino Fundamental e Médio foi possível verificar a função e atuação do coordenador na escola.

A maioria dos entrevistados descreveu que em sua prática cotidiana as maiores dificuldades encontradas são de se relacionar com o corpo docente e de articular suas ideias com as propostas da escola, além de encorajar a participação de todos, inclusive da família, na realização de projetos.

"O coordenador pedagógico precisa desempenhar muitas funções, ser um pouco de tudo, professor, artista, conciliador, psicólogo, líder, organizador, supervisor, entre outros."

(Trecho retirado do questionário aplicado ao Coordenador Pedagógico 1)

Na relação entre família e escola o coordenador pedagógico faz-se necessário, pois esse profissional é requerido para estreitar laços e mantê-los em prol da formação efetiva dos educandos à medida que cada instância assuma seu papel social diante desse ato indispensável e intransponível.

"Procuro fazer o elo, a ligação entre família e escola, através do atendimentos aos pais, dos textos enviados para casa (reflexões), através do blog da Escola Infantil, das reuniões, do grupo e do contato cotidiano."

(Trecho retirado do questionário aplicado ao Coordenador Pedagógico 4)

"Transmitir clareza e segurança para a realização da proposta pedagógica da escola."

(Trecho retirado do questionário aplicado ao Coordenador Pedagógico 7)

Assumir esse cargo é sinônimo de enfrentamentos e atendimentos diários a pais, funcionários, professores, além da responsabilidade de incentivo a promoção do projeto pedagógico, necessidade de manter a própria formação, independente da instituição e de cursos específicos, correndo o perigo de cair no desânimo e comodismo e fatores de ordem pessoal que podem interferir em sua prática. 
"Creio que a minha maior função como Coordenadora Pedagógica é utilizar de muito DIÁLOGO, COMPREENSÃO E PARCERIA na relação com pais, professores, alunos e funcionários."

(Trecho retirado do questionário aplicado ao Coordenador Pedagógico 1)

O coordenador pedagógico é peça fundamental no espaço escolar, pois busca integrar os envolvidos no processo ensino-aprendizagem mantendo as relações interpessoais de maneira saudável, valorizando a formação do professor e a sua, desenvolvendo habilidades para lidar com as diferenças com o objetivo de ajudar efetivamente na construção de uma educação de qualidade.

\section{CONSIDERAÇÕES FINAIS}

O desafio que constatamos no desenvolvimento da pesquisa permitiu um conhecimento sobre as reais funções do coordenador pedagógico, sobre sua função na coformação e supervisão dos processos de ensino aprendizagem de professores e alunos, compreendendo quais são as prioridades que o coordenador deve atender no seu cotidiano, detectando também quais os desafios encontrados na realização do seu trabalho.

Para isso investigamos o tema em diferentes fontes: livros, pesquisas in loco, artigos, a fim de tornar significativa e prazerosa a realização dessa pesquisa.

Conclui-se que falar do coordenador pedagógico e de suas ações junto ao corpo docente e demais membros da comunidade escolar, é uma forma de dar sentido ao profissional especialista, cujas atribuições constata-se uma grande indefinição, pois, na maioria das vezes, o coordenador desempenha outras funções dentro da escola deixando as suas reais funções de lado, ficando este sobrecarregado nas suas atribuições específicas. Esse desvio de atuação proporciona uma dificuldade na concretização dos objetivos curriculares que atendem de fato aos anseios de uma educação significativa.

Com essa pesquisa foi possível identificar a ação da coordenação pedagógica em uma atuação motivadora, inovadora e interdisciplinar, característica da prática desse profissional que busca sempre inovar e transformar o processo de ensino e aprendizagem por meio de uma prática participativa que envolva os agentes da educação.

Faz-se necessário, portanto, a garantia de um ambiente democrático e com divisão de responsabilidades, de forma a despertar a consciência daqueles que se engajam no campo educacional para transformar o cotidiano escolar em algo realmente prazeroso e significativo.

No entanto, é necessário que o coordenador esteja atento aos desafios encontrados em sua prática cotidiana, conhecer o universo da educação, suas dificuldades e avanços, fazendo, a partir de sua atuação pedagógica, um caminho de maturação, vivenciando as experiências da 
comunidade escolar como processo individual dos sujeitos que dela participam, mas, visando essa ação como uma abrangência de transformação coletiva.

\section{REFERÊNCIAS}

CLEMENTI, Nilba. A voz dos outros e a nossa voz. In.:ALMEIDA, Laurinda R., PLACCO, Vera Maria N. de S. O coordenador pedagógico e o espaço de mudança. São Paulo: Edições Loyola, 2003.

GUIMARÃES, A.A.; VILLELA, F.C.B. O professor-coordenador e as atividades de início de ano. In: BRUNO, E.B.; ALMEIDA, L.R.; CHRISTOV, L.H.S. (orgs.). O coordenador pedagógico e a formação docente. São Paulo: Edições Loyola, 2000, p. 37-54.

LEITE, S.A.S. Desenvolvimento profissional do professor: desafios institucionais. In: AZZI, R.G.; BATISTA, S.H.S.S.; SADALLA, A.M.F.A. (orgs.). Formação de professores: discutindo o ensino de Psicologia. Campinas: Alínea, 2000, 39-66.

NÓVOA, A. Professor se forma na escola. Revista Nova Escola, São Paulo, n.142, mai., 2001.

PLACCO, V.M.N.S. Formação e prática do educador e do orientador: confrontos e questionamentos. Campinas: Papirus, 1994. 